\title{
Balkanologie
}

Balkanologie Revue d'études pluridisciplinaires

Vol. VIII, $n^{\circ} 2$ | 2004

Volume VIII Numéro 2

\section{Aux origines du conflit yougoslave : 1980-1992}

The origins of the Yugoslav conflict: 1980-1992

\section{Zoran Kosanic}

\section{OpenEdition}

Journals

Édition électronique

URL : http://journals.openedition.org/balkanologie/543

DOI : $10.4000 /$ balkanologie. 543

ISSN : 1965-0582

\section{Éditeur}

Association française d'études sur les Balkans (Afebalk)

\section{Édition imprimée}

Date de publication : 1 décembre 2004

ISSN : 1279-7952

\section{Référence électronique}

Zoran Kosanic, «Aux origines du conflit yougoslave : 1980-1992», Balkanologie [En ligne], Vol. VIII, n 2 | 2004, mis en ligne le 20 janvier 2010, consulté le 17 décembre 2020. URL : http:// journals.openedition.org/balkanologie/543 ; DOI : https://doi.org/10.4000/balkanologie.543

(ㄷ) Tous droits réservés 


\title{
AUX ORIGINES DU CONFLIT YOUGOSLAVE : 1980-1992
}

\author{
Zoran Kosanic*
}

L'historiographie récente de la Yougoslavie contemporaine a mis en évidence les ruptures politiques, économiques et sociales qui ont préfiguré les guerres des années 1990, et qui ont embrasé cet État des Balkans. La complexité du cadre politique et culturel yougoslave, son insertion dans la géopolitique internationale ainsi que la proximité des événements, ont largement influencé la lecture des événements passés et présents. C'est pourquoi l'étude de la Yougoslavie, en tant que sujet politique, fait encore l'objet d'âpres débats d'idées où se concentrent l'essentiel des paradigmes socio-politiques contemporains. Notre approche a privilégié la multidimensionnalité des facteurs politico-économiques en tant que moteurs des interactions sociales, chaque tension ayant pour corollaire une série de conséquences systémiques que l'on inclut dans l'analyse générale du fonctionnement d'un État en tant que structure, et ses rapports à la population, sans négliger l'influence déterminante des hommes, dynamique de l'Histoire.

Tito, symbole de la deuxième Yougoslavie, décède en 1980. Or, sans Tito la fédération se révèle rapidement vidée de son pouvoir propre, l'ensemble des prérogatives de l'État ${ }^{1}$, étant transféré aux républiques. Le Parti, qui était garant non seulement de la Constitution mais aussi de l'idéologie, subira la même évolution. La multiplication des États va aussi multiplier les partis. Dès 1981, la fédération entre dans une crise globale et se révèle incapable de constituer le ciment de la société yougoslave. La bureaucratie, qui s'est agrégée aux structures de l'État, ne pouvait pas se démocratiser sans prendre le risque d'être balayée lorsque les aspirations au changement se feront sentir en

\footnotetext{
- Doctorant inscrit à Paris 4, zorankosanic@voila.fr
}

${ }^{1}$ Le terme serbe de položaj drżave, renvoyant à la notion anglaise " statehood ", serait plus précis. 
Yougoslavie. Les tentatives balbutiantes de démocratisation, inspirées par l'élite intellectuelle, seront détournées de leur cours pour se muer en revendications nationales. Les apparatchiks du Parti, pour se maintenir au pouvoir, opéreront le revirement idéologique nécessaire afin de conserver leurs privilèges ${ }^{2}$. Ainsi, en termes strictement politiques, si la délitescence des structures fédérales et la récupération d'un malaise social a permis l'apparition de phénomènes nationalistes, leur diffusion à grande échelle n'a pu se mettre en place que grâce à l'infléchissement puis au soutien de l'appareil d'État. La Yougoslavie existait-elle réellement, du point de vue des sentiments nationaux ? La concordance et l'évolution des événements en Yougoslavie nous permet de soulever la question des institutions et de la société yougoslave, en tant qu'unité ou pluralité structurelle et sociologique. La volonté de se démarquer politiquement des pays socialistes a conduit la Yougoslavie vers une voie économique originale - l'autogestion ouvrière - censée conférer aux travailleurs une maîtrise directe sur leur production. La crise économique des années 1980 marque l'échec d'une économie hybride, ni socialiste dans le sens où la reproduction sociale totale, régulée par une redistribution égalitaire des richesses, n'est pas effective, ni capitaliste, car ne répondant pas aux normes du marché, incluant la libéralisation des prix, répondant aux lois de l'offre et de la demande, et la possibilité de faire faillite en cas de pertes sèches. En ce sens se pose la question des rapports de la Yougoslavie au marché mondial. La faillite du système autogestionnaire le symbolise tout autant : le cloisonnement des marchés régionaux, l'absence de politique concertée au niveau des républiques et, en amont, la primauté de la fédération dans la formulation de la politique économique, ainsi que l'opacité d'un système non confronté à des enjeux économiques clairement définis ${ }^{3}$. La décrédibilisation progressive de l'idéologie socialiste a, en effet, révélé les tares essentielles du régime mis en place par Tito : l'absence d'une conscience citoyenne. L'ethnocentrisme comme valeur, relayé par les médias, récupéré par le Parti, marque la rupture fondamentale avec le modèle de société instauré par Tito. L'instrumentalisation de l'appareil d'État et des médias, par les personnalités politiques clés au sein des républiques, a permis d'orienter les frustrations des masses. D'ennemis invisibles agrégés aux structures de l'État, les populations ont identifié les maux à travers les autres nations composant l'espace yougoslave. Dès lors que les répu-

\footnotetext{
${ }^{2}$ L'étude récente de Jović (Dejan), Jugoslavija - Država koja je odumrla. Uspon, kriza i pad četrvte Jugoslavije (Yougoslavie - l'État qui s'est désagrégé. Ascension, crise et chute de la quatrième Yougoslavie), Beograd : Samizdat B 92, 2003, qui met l'accent sur l'aspect idéologique sincère de la société yougoslave et de son élite, mérite cependant toute notre attention tant du point vue méthodologique que de son approche novatrice de la crise yougoslave.
}

3 À ce titre, lire les travaux exemplaires de C. Samary, notamment Samary (Catherine), Le marché contre l'autogestion : l'expérience yougoslave, Paris / La Brèche : Publisud, 1988. 
bliques se sont tournées les unes contre les autres, les instances fédérales ont périclité, faute de pouvoirs coercitifs. Les élections pluripartites dans les différentes républiques, loin d'implanter la démocratie en Yougoslavie, ont d'une part pérennisé l'ancienne nomenklatura par le mensonge et l'appel à la haine, mais aussi justifié les politiques unilatérales et sécessionnistes des différentes composantes de la fédération. Les conséquences effectives pour les instances fédérales et leurs différents organes ont été multiples, mais la manifestation finale s'est traduite par leur paralysie, voire leur disparition. Il en a été ainsi de l'armée (JNA), pivot de la Yougoslavie, garante de sa Constitution et de son unité. Face à la dissolution violente de la Yougoslavie, les États-Unis, puis la Communauté européenne, tout d'abord attentistes et unis, se dispersent dans une cacophonie de voix discordantes. L'impuissance politique et diplomatique de l'Europe se manifeste tout au long de l'année 1991, et se révèle finalement dramatique de conséquences pour la Yougoslavie elle-même, toutes deux victimes de leurs faiblesses institutionnelles, bien qu'à des degrés différents. Nonobstant la réalité politique locale, faut-il définir la politique bancale de la Communauté européenne comme un défaut de connaissance du contexte yougoslave et balkanique ou comme un choix délibéré d'une passivité coupable, dont les objectifs non avoués se situaient au sein même des chancelleries occidentales ?

Nous établissons les limites du sujet à l'année 1992 qui incarne l'aboutissement du processus de désagrégation définitive de la Yougoslavie et son basculement dans le conflit civil avec la guerre transposée en Bosnie-Herzégovine. Dès lors, s'ouvre un nouveau chapitre du conflit yougoslave, redéfinissant sa dimension et ses conséquences nationales ainsi qu'internationales. Ainsi, la période charnière de 1980-1992 permet tout autant de cerner l'aboutissement du processus comme de la gestion de la crise des années post-titistes, que la conjonction des facteurs politiques, économiques et humains ayant fait sombrer le pays dans le chaos.

\section{QUEL AVENIR POUR LE FÉDÉRALISME YOUGOSLAVE APRES TITO ?}

La deuxième Yougoslavie marque la victoire des éléments unificateurs durant la seconde guerre mondiale, qui s'inscrivent dans l'idéal communiste représenté par Josip Broz Tito (1892-1980). Cette unification fut rendue d'autant plus nécessaire que les massacres perpétrés dans l'espace yougoslave et balkanique 4 ont vidé cette région de $10 \%$ de sa population entre 1939 et 1945 . Les populations, 
exsangues, confrontées à un choix politique et historique, ont maintenu leur confiance et placé leur destinée entre les mains d'un appareil d'État structuré et discipliné, le plus crédible et le mieux à même de reconstruire un espace pacifique et commun.

La seconde guerre mondiale a néanmoins laissé des traces profondes et des ressentiments durables, dans le vécu comme dans l'imaginaire des peuples composant la République Socialiste Fédérative de Yougoslavie (RSFY). Le nouveau pouvoir a dũ composer avec les aspirations des différentes populations, dont l'histoire et le patrimoine culturel généraient plus d'éléments dissolvants qu'unificateurs. Ainsi, si la Yougoslavie est reconstruite sur une base fédérale, issue des décisions adoptées lors des sessions de l'AVNOJ5, embryon du futur gouvernement, ses frontières administratives, internes comme externes, répondent à une tentative d'équilibrer les aspirations des différentes nations constitutives et constituantes de Yougoslavie, et faire échec à toute tentative d'hégémonie d'un peuple sur d'autres dans l'espace commun ${ }^{6}$. À cet aspect national s'ajoute, par la suite, la " question nationale ", préoccupation essentielle pour les élites politiques comme pour les différents peuples qui constituent la fédération, tant du point de vue politique qu'économique et socio-culturel. De par la structure même de la fédération yougoslave, multinationale, et l'incessante quête de nouvelles formes "d'égalité en droit " et d'équilibre des forces entre les unités politiques et ethno-nationales $" 7$, clé de voûte de la construction yougoslave de Tito, la citoyenneté, identifiée à la nation, n'a pas permis la responsabilité citoyenne se définissant dans l'orientation globale de l'État. Il était naturel pour les populations majoritaires de s'identifier à leur propre nation, sachant que leur république nominative ou constitutive pouvait orienter les grandes lignes politiques et idéologiques de la fédération. Les minorités, jalouses de leurs droits, ou de peur de se voir assimilées aux nations dominantes, cultivaient une position identique. L'équilibre entre ces nationalismes exigeants reposait sur trois piliers fondamentaux : le slogan communiste " unité et fraternité ", le rôle dirigeant de la $\mathrm{LCY}^{8}$, et le socialisme yougoslave fondé sur l'autogestion.

\footnotetext{
${ }^{5}$ Antifašističko veće narodnog oslobodjenja Jugoslavije, Conseil antifasciste de libération populaire de la Yougoslavie. D'autre part, les frontières de l'AVNOJ, arbitraires et réfléchies, sont les frontières des actuelles Républiques et Provinces issues de l'ex-Yougoslavie.

${ }^{6}$ Cette notion renvoie à l'idée, d'une part, d'opposition entre les Serbes et les Croates, populations les plus nombreuses de Yougoslavie et, d'autre part, de garantie vis-à-vis des autres peuples et minorités face aux éventuelles prétentions hégémoniques des premiers cités.
}

\footnotetext{
7 Pesic (Vesna), "La guerre pour les États nationaux ", in Popov (Nebojša), éd., Radiographie d'un nationalisme. Les racines serbes du conflit yougoslave, Paris : Editions de l'Atelier, 1998, p. 12.
}

${ }^{8}$ LCY, Ligue des Communistes de Yougoslavie. Il en va de même pour LC, Ligue des Communistes. 
Les différentes constitutions yougoslaves de l'après-guerre soulignent les errements de la classe politique, concernant non seulement l'orientation nationale de la Yougoslavie mais aussi la définition du rôle de la fédération, dont le moteur aussi bien idéologique qu'institutionnel intrinsèque reste, et doit rester, le Parti. L'aboutissement de la philosophie politique yougoslave, dans ses principes comme dans son fonctionnement, devait répondre à deux exigences essentielles. Il s'agissait d'assurer, d'une part, une représentation égale des différents peuples de Yougoslavie à travers leurs entités territoriales strictement définies par la Constitution de 1974, la dernière de la Yougoslavie issue de l'AVNOJ ; d'autre part, la pérennité de la Yougoslavie après Tito, l'élément coordinateur restant la toute puissance du Parti, à travers ses différents relais.

L'un des éléments déterminants de la Constitution de 1974, effective dès le décès de Tito, introduit l'idée que le pouvoir de la fédération émane à présent des républiques, et non l'inverse, et l'on pourrait ajouter que la fédération est une émanation des républiques. Cette constitution sanctionne l'épanouissement des nations et nationalités en tant que communautés unies au sein d'une fédération de communautés. Ainsi, la fédération est une communauté d'intérêts différents, se réalisant dans un espace fédéré. Elle n'est plus l'émanation propre d'une communauté se réalisant dans un seul et même espace. En reconnaissant aux républiques fédérées le caractère d'États quasi-souverains, la constitution officialise bel et bien la création d'une Confédération yougoslave. À partir de 1980, la question au sein des plus hautes sphères du gouvernement fédéral, comme des Républiques et Provinces autonomes, est de trouver un langage et une orientation politique communs, afin d'assurer le fonctionnement de la RSFY.

Les pouvoirs coercitifs de la fédération étant très limités, du fait du transfert des compétences en matière décisionnelle au profit des républiques, selon un principe de subsidiarité des fonctions et décisions, une partie des élites politiques réclame tout au long de la période 1980-1986, une série de mesures replaçant la fédération dans son rôle de régulateur dans l'harmonisation des intérêts républicains. Dans chacune des six républiques et provinces, les hauts fonctionnaires de ces instances régionales administrent des États quasi-souverains. À travers les dispositions de la Constitution de 1974, ces " référents " d'une même ligne politique, chacun menant celle de son propre État, " délèguent " au niveau fédéral l'un de leurs membres pour représenter la ligne politique de leur république. Ce pluralisme d'apparatchiks ambitieux constitue l'essentiel de la démocratie yougoslave. Ces liens par trop ténus qui les unissent, laissent supposer la fragilité de l'État qui les réunit. D'autre part, la fragilité de la fédération pousse chaque groupe de pression à revendiquer l'égalité stricte entre les membres de cette caste, et à surveiller les autres pour empêcher toute velléité de pouvoir personnel. 
Face à la gabegie du système, la société yougoslave évolue dans un sens où transparaissent, sans discernement, volonté de démocratisation du régime de tendance libérale ou réformiste socialiste - nationalisme des élites comme des institutions religieuses, et mécontentements des masses face à la crise économique. À partir de 1980, l'anarchie qui règne au sein de l'État permet une libéralisation partielle de "l'opinion publique ", non voulue par la direction de l'appareil d'État. Ces voix discordantes, dont l'écho se répercute à travers les différentes couches sociales, déstabilisent une bureaucratie très vite placée sur la défensive. La liberté de ton des journalistes, comme les sujets proposés, heurtent de plein fouet une bureaucratie peu habituée aux scandales publics. La contestation envers le régime se cristallise d'autre part, dans les milieux intellectuels, autour des cercles universitaires et artistiques, dans l'ensemble de la fédération et sous diverses formes. Mais si la bureaucratie politique, ellemême divisée et incapable de se restructurer, peine à définir une ligne de conduite pour l'ensemble de la société yougoslave, l'opposition au régime, qui n'est ni structurée ni unie (que ce soit idéologiquement ou dans un embryon de parti alternatif) forme, quant à elle, une " véritable mosaïque " où les différents courants sont souvent "plus distants les uns des autres qu'ils ne le sont séparément des autorités en place $" 9$.

La Yougoslavie des années 1980 connaît une crise économique continue. Le système dans son ensemble est à la limite de la faillite. Or, si la prise de conscience tardive des élites politiques a pu enfoncer le pays dans une crise économique sans précédent pour le régime, la marge de manœuvre de l'État ne permet que des plans d'austérité qui ne modifient pas en profondeur un système impossible à réformer sans par là même saper les fondements de la construction fédérale. Se met en place dès lors une économie anarchique, impossible à maîtriser, où alternent les " plans de sauvetage " et les nécessaires " plans d'austérité ", dans lesquels une population apprend à penser dans la crise. La fragmentation progressive de la fédération yougoslave, dont la base constitutionnelle a permis la création d'autant d'économies distinctes que de républiques et de provinces, d'une part, a accentué les disparités régionales et, d'autre part, a paralysé la capacité de la fédération de se réformer pour véritablement s'insérer dans le marché mondial. Le " compartimentage " des économies régionales symbolise la suprématie d'une bureaucratie décentralisée où les critères de cohérence économiques sont avant tout politiques ${ }^{10}$. Ces frontières " invisibles " mais " réelles " entre les républiques et les provinces

\section{Libération, 6 mai 1980.}

${ }^{10}$ Dans le même ordre d'idée, le cas du conglomérat Agrokomerc, dont les malversations financières sont révélées en 1987, est l'exemple type de l'imbrication des élites politiques et des cadres d'entreprise dont les montages financiers servaient essentiellement un clientélisme bureaucratique. Comment dès lors réformer un système dont une grande partie de ses membres tire un profit immense ? 
constituant la fédération yougoslave, ont largement pénalisé l'économie interne et externe de la Yougoslavie. De même, durant les années 1980, la volonté des élites politiques de réformer le complexe industriel s'est heurtée à l'héritage constitutionnel et juridique de la Yougoslavie titiste. Ces éléments socioéconomiques cristallisent les principaux problèmes de la fédération : son incapacité à gérer l'idéologie et les nationalismes qui s'affrontent en son sein, ainsi que les clivages entre régions riches et pauvres, chacun étant aveuglé par ce qu'il considère comme une spoliation de biens propres : les uns car ils croient être exploités par une riche caste d'exploitants, les autres parce qu'ils croient travailler pour tout le monde. Ainsi, lorsqu'il a été question de réformer en profondeur le mécanisme complexe des acquis socio-politiques, il est apparu clairement que le système rigide de l'État-parti devait lui-même se réformer. La crise de l'autogestion est ainsi, dans le même ordre d'idée, une crise de la fédération.

\section{LA MUTATION NATIONALISTE DE L'ESPACE YOUGOSLAVE}

La période 1984-1987 marque véritablement une transition entre l'ancien régime et les tentatives d'établissement d'un ordre nouveau, d'où vont émerger des aspirations antagonistes et des conceptions inconciliables sur la perception de l'avenir de l'espace yougoslave. Les manifestations de rejet de la fédération, qui se sont muées en nationalismes, résultent d'une réflexion d'ensemble de toute l'élite intellectuelle, qui a modifié, canalisé et médiatisé les mécontentements et la frustration d'une population qui réclamait avant tout une réponse réelle à ses problèmes quotidiens et immédiats, et un retour à la prospérité.

Chaque république connaissait une tendance générale vis-à-vis des projets de réformes constitutionnelles et économiques. Les républiques les plus importantes, pour des raisons économiques et historiques, et dont les antagonismes monopolisaient les débats, restaient cependant la Serbie, la Croatie et la Slovénie. La question essentielle en Serbie consistait à redéfinir ses rapports avec ses Provinces autonomes, et à surmonter ses contradictions institutionnelles, principale cause, selon ses responsables politiques, de son manque de productivité et de dynamisme économique ${ }^{11}$. En ce sens, les cadres politiques de la République de Serbie étaient partisans d'un renforcement de

\footnotetext{
${ }^{11}$ Cette volonté de refonte des institutions est au centre de l'activité politique de la RS de Serbie depuis le milieu des années 1970. Il est vrai que les gouvernements de Voïvodine et du Kosovo pouvaient opposer leur veto aux projets de loi présentés au parlement républicain de Serbie, sans que celle-ci puisse intervenir dans les affaires internes de ces dernières.
} 
la fédération et du marché yougoslaves. La république de Croatie menait une politique se situant entre celle de la Serbie et celle de la Slovénie. Ses cadres conservateurs s'attachaient essentiellement à maintenir l'ordre existant au niveau fédéral, tout en essayant de régler les problèmes internes de la république. La Slovénie, quant à elle, principale bénéficiaire de la politique à l'exportation, prônait une démarche libérale d'ancrage à l'économie occidentale. République la plus riche, détenant les entreprises les plus compétitives et les plus rentables, capables de surmonter la politique d'austérité préconisée par la fédération, ses dirigeants politiques n'ont eu de cesse d'affirmer leur indépendance vis-à-vis de la fédération. Ainsi, jusqu'en 1987, les maillons faibles de la fédération semblent être la RS $^{12}$ de Serbie, qui ne peut exprimer une " voix cohérente au sein de la fédération yougoslave "13, car trop dépendante de ses Provinces autonomes, et la RS de Slovénie dont la politique " privée " ressemble à celle d'un État indépendant.

Or, le nationalisme des différentes populations composant l'espace yougoslave, étouffé sous l'ère Tito, n'a jamais cessé de se manifester. Le nationalisme serbe, durant tout l'après-guerre, n'était ni le plus virulent, ni le plus destructeur. Les événements du Kosovo de mars-avril 1981 ont directement réactivé des peurs ainsi que des angoisses telles que le ressentiment serbe visà-vis du nationalisme albanais au Kosovo a amené les Serbes à s'interroger sur leur véritable place au sein de cette fédération, dont un nombre croissant dénonce l'anti-serbisme. Le mécontentement croissant des Serbes au sein de la fédération a été récupéré aussi bien par une partie de l'élite intellectuelle que par l'Église orthodoxe. Dans cette mutation progressive vers une radicalisation des masses, les intellectuels vont jouer le rôle de moteur et de centralisateur des revendications ${ }^{14}$. Ce nationalisme offensif, relayé par les médias, se traduit par des manifestations de mécontentement croissantes au Kosovo et en Serbie, justifiant par là même leurs craintes du nationalisme des nations et nationalités des autres républiques. Car " si les nationalistes des différentes nations et nationalités s'affrontent, ils œuvrent en fait, à un projet commun : la destruction de la Yougoslavie $" 15$.

Le nationalisme s'est exprimé et développé différemment suivant les républiques. De " l'élitisme " intellectuel et économique en Slovénie, à travers l'extrême droite idéologique et religieuse en Croatie, le renouveau de l'Islam

${ }^{12}$ RS, République Socialiste.

${ }^{13}$ Tomic (Yves), « La Ligue des communistes de Serbie et l'ouverture de la question nationale serbe 19771987 ", Balkanologie, 3 (1), septembre 1999, p. 94.

14 Ce nationalisme serbe est résumé, comme stigmatisé, à travers le mémorandum de l'Académie des Sciences et des Arts de Serbie (SANU), commandé en 1985 et paru par fragments les 24 et 25 septembre 1986 dans Večernje Novosti.

${ }^{15}$ Stambolić (Ivan), Put u bespuće (Voyage vers nulle part), Beograd : Radio B92, 1995. 
balkanique en Bosnie-Herzégovine ou la polarisation de la " tradition clanique " au Kosovo et en Macédoine, l'appareil politique des différentes régions a réagi de façon fragmentée et indépendante. L'absence d'unité de décision au niveau fédéral a amené chaque république à gérer ses excès nationaux, en fonction de ses intérêts, mais aussi des initiatives populaires et intellectuelles. Faute de consensus et d'approche globale dans la nécessaire démocratisation du pays comme pour le règlement du danger nationaliste, ce dernier a fleuri au point que l'imbrication nationale-démocrate est devenue l'alternative la plus crédible du changement. À l'image de la Serbie, la démocratisation intellectuelle a créé une rupture d'équilibre dans la sphère du pouvoir, propulsant les éléments les plus virulents en son sein. L'idée yougoslave, moribonde, et son véhicule, la LCY, opèrent dans cette période leur mue nationale.

Alors que jusqu'en 1986, le problème du Kosovo, ainsi que la position de la Serbie vis-à-vis de ses provinces autonomes, revêtaient un caractère institutionnel, visant avant tout à réunifier la Serbie afin de rationaliser l'économie des trois entités et pacifier socialement les régions, l'année 1987 marque un tournant historique. Il s'agit dès lors de changer la Constitution pour unifier le peuple serbe à l'intérieur de la République socialiste de Serbie. Cette mutation, préparée depuis le début des années 1980, a bénéficié de circonstances extraordinaires, mais aussi du soutien de personnages " clés ", sans lesquels l'apparition d'un leader incontesté aurait été verrouillée. L'opposition de deux courants au sein des différentes instances de la bureaucratie " rouge ", l'un et l'autre conservateurs, mais divergeant sur les moyens de résoudre la crise, a atteint son apogée lors de la $8^{\text {ème }}$ session de la LC de Serbie à l'automne 1987, qui voit la victoire des partisans de la manière forte sur les tenants de la continuité ${ }^{16}$. Les règlements de comptes politiques au sein du Parti, orchestrés par médias interposés, ont été rendus possibles grâce au renversement des valeurs " socialistes " opéré par les différents acteurs du conflit. La victoire de Milošević sur ses " concurrents ", bien que s'inscrivant dans la continuité des manœuvres de pouvoirs, constitue le premier acte du démembrement des principes fondamentaux du régime post-titiste, et, in extenso, de la fédération yougoslave : l'équilibre du pouvoir et son contrôle collectif.

Le débat autour de la réforme de la Constitution prend, fin 1987-début 1988, la forme d'une opposition radicale entre une RS de Serbie dont Milošević s'adjuge peu à peu la haute main, et la RS de Slovénie, dont l'appareil d'État tente de convaincre les autres républiques, notamment la Croatie, du danger que représentent l' " unitarisme " serbe et tout retour au centralisme.

\footnotetext{
${ }^{16}$ La victoire de Milošević lors de cette session marque le début d'une nouvelle ère politique. Loin de s'enfoncer dans une crise politique, Milošević, soutenu en cela par une présidence qu'il réorganise, et par les médias dont il s'assure la mainmise en excluant tous les éléments contrecarrant ses projets, conforte sa position de leader, et se pose en continuateur de l'idéal " titiste n, tout en récupérant le " dossier Kosovo n.
} 
Milošević organise pendant cette période un nouvel ordre politique qualifié de " révolution antibureaucratique ", alternant la pression sur les personnalités gênantes avec un discours populiste, appelant au renversement des apparatchiks, et la pression sur les institutions par l' " homogénéisation socialiste " dont il serait l'épicentre. À ce moment-là, les bases de la Yougoslavie " socialiste et autogestionnaire " sont détruites. La désunion croissante des membres de la LCY, leur impuissance à modifier la politique de " réunion nationale " qui s'opère en Serbie, au mépris de l'esprit de la Constitution qui interdisait la primauté d'une nation sur les autres, et l'orientation sécessionniste de la RS de Slovénie qui s'engage peu à peu sur la voie d'une indépendance de fait et réfléchit sur son indépendance de droit, fait de la RSFY " un mort en sursis ".

Les bouleversements institutionnels ne se résument cependant pas uniquement à un rapport de force entre bureaucraties concurrentes, car ils se superposent à un malaise réel au sein de la société yougoslave. Le nœud gordien de la contestation sociale en Yougoslavie repose sur un fonds de crise économique et idéologique d'une population lasse d'uniformité politique et de promesses vaines. La croissance négative de l'économie, la baisse considérable de la production nationale, le défaut d'investissement ainsi qu'une inflation galopante ${ }^{17}$, ont radicalisé des " masses laborieuses " qui aspiraient à des changements sans en subir les conséquences. Le taux de chômage, incompatible avec les préceptes supposés du plein emploi dans une société " communiste ", auquel s'ajoute le désœuvrement d'une jeunesse déçue du manque de perspectives professionnelles, crée un climat favorable aux discours populistes promettant des changements rapides et efficaces. La focalisation sur le Kosovo a permis d'unifier les différentes nationalités derrière leurs dirigeants respectifs, tout en rejetant les griefs et les tares du régime sur les " autres".

L'instrumentalisation du Kosovo, qui a permis la remise en question des rapports de pouvoir au sein de la RSFY, a tout autant permis aux différents nationalismes de s'exprimer de façon ouverte et pratique dans leurs différentes composantes que la mise en place d'une structure étatique libérée de ses contraintes sociales ${ }^{18}$. La pression exercée par la violence d'État, dite " légitime ", sur la population albanaise du Kosovo a pu par la suite se renouveler sur l'ensemble du territoire, au détriment de toutes les minorités. Ainsi, si la population serbe du Kosovo a réellement eu à subir des brimades de la part de la population albanaise, que ce soit le fait d'éléments isolés ou de l'inaction et

\footnotetext{
${ }^{17}$ Le taux d'inflation, qui atteint $170 \%$ en 1987 , culmine à des chiffres records de $2500 \%$ en 1989 . Outre le fait que l'hyper-inflation ronge l'ensemble de l'économie, elle crée une situation intenable au quotidien pour la population qui ne peut plus consommer normalement. Elle crée par ailleurs un marché parallèle où les échanges s'effectuent en devises stables, contribuant ainsi au cycle de crise économique.
}

${ }^{18}$ Cette évolution marque une rupture entre l'État et sa population, tout autant qu'une identification des masses à une politique " nationale " de l'État. Elle ouvre la voie à une forme de dictature oppressive et violente vis-à-vis de tous les ennemis supposés ou identifiés comme tels. 
l'indolence du gouvernement local, elle subit en retour la terreur d'un pouvoir plus fort et plus déterminé, celui de la Serbie proprement dite. À partir de 1989, la radicalisation des manifestations au Kosovo aboutit à la banalisation de la mort comme à la déshumanisation des individus.

Cette politique de refonte du ciment social a pu se mettre en place, en partie, grâce à la manipulation des sens et de l'émotion des individus à travers les médias. La structure pyramidale du pouvoir a permis à l'élite politique, principalement en Serbie, puis dans les autres républiques et sous des formes similaires ${ }^{19}$, de " récupérer " les rédactions de la presse écrite et audiovisuelle en changeant leurs cadres dirigeants ${ }^{20}$. La chaîne s'est ensuite déliée jusqu'aux journalistes et aux éléments subalternes exécutants. Le même processus de renversement des cadres (par allégeance ou mutation) s'est effectué, dans les entreprises puissantes comme dans les secteurs clés de l'industrie. Les organisations syndicales, simple courroie de transmission entre l'État et la base ouvrière, se sont révélées extrêmement précieuses dans les mots d'ordre transmis du " haut " vers le " bas ". Sans un Parti structuré et centralisé au niveau républicain, la propagande du pouvoir dominant aurait plus difficilement atteint ses objectifs politiques ${ }^{21}$.

La propagande de l'appareil d'État dans les différentes républiques de Yougoslavie a opportunément et subtilement préparé la population à la guerre. Les discours des représentants politiques, les médias et les manifestations culturelles, ont catalysé par la représentation symbolique et l'imagerie guerrière un mode de différenciation et de rejet des " autres " nations et nationalités. Cette violence des idées, matérialisée par des actes de guerre et la victimisation des agresseurs, la provocation comme l'exagération des drames subis individuellement ou collectivement, a surtout été utilisée en Serbie, en Croatie et en Bosnie-Herzégovine. Cela a permis l'unification et l'adhésion des populations par la peur. Les médias ont largement contribué, par le choix des sujets et la violence des images, comme par la désinformation ou l'instrumentalisation des faits, à donner une vision orientée, tronquée ou fausse de la situation de la Yougoslavie, comme de sa population ${ }^{22}$. La propagande émotionnelle populaire

${ }^{19}$ Le cas de la Slovénie, pour des raisons historiques, politiques et économiques, est sensiblement différent.

${ }^{20}$ Les directeurs du quotidien Politika, Živorad Minović, et de la chaîne de télévision RTS (Radio Télévision de Serbie), Dušan Mitević, puis Ratomir Vico, sont les exemples types d'avatars du régime mis en place par Milošević en Serbie.

${ }^{21}$ En Croatie, pour des raisons essentiellement externes (la crainte de la politique en Serbie, l'influence de la Slovénie, la rébellion des Serbes de Slavonie orientale et de la Krajina, etc.), le Parti a été " renversé n par un ancien cadre militaire, Franjo Tudjman, soutenu financièrement par une partie de la diaspora nationaliste croate.

22 " Si les gens définissent des situations comme réelles, elles sont réelles dans leurs conséquences ", in Merton (Robert), Social Theory and Social Structure, New York : The Free Press, 1968, pp. 475-480. Voir aussi Pesic (Vesna), art.cit., p. 53. 
s'est matérialisée par de grandes manifestations de masse, les meetings de la vérité en Serbie, dans les provinces autonomes, au Monténégro dès 1988 et audelà, organisés et orchestrés par les politiciens les plus virulents. Le mélange de persuasion et de menaces vis-à-vis de l'ennemi abhorré a transcendé les foules comme les électeurs passifs, créant une symbiose étroite dans la notion d'unité d'un " peuple " face à l'ennemi commun. Cette distanciation par le populisme a permis aux dirigeants et à ceux qui aspiraient à diriger ${ }^{23}$, grâce à l'appareil d'État, d'étouffer toute opposition, sur le terrain comme à travers les voies de communication. Le mot d'ordre était : " Il n'y a pas d'alternative ! [à la voie vers laquelle nous vous conduisons...]".

\section{LA MARCHE VERS LA GUERRE}

La victoire des tenants du nationalisme sur fond d'élections " démocratiques " est tout aussi révélatrice de l'état d'esprit des populations durant la période 1989-1990. L'ordre des élections dans les républiques est lui aussi un élément explicite, tant des manœuvres de pouvoir, que de la formulation des choix futurs des républiques. Dans les républiques de Slovénie et de Croatie, les partis d'opposition constitués incluaient comme élément central de leurs programmes l'indépendance des républiques ${ }^{24}$. Leur victoire fut présentée comme le choix de la population de se retirer de la fédération. Dès lors, les élections qui suivirent en Macédoine et en Bosnie-Herzégovine reflétèrent le climat de méfiance généralisée, chacune des nations et nationalités votant pour ses propres représentants nationaux ${ }^{25}$, et non pour un programme politique et économique citoyen ${ }^{26}$. Enfin, les élections en Serbie et au Monténégro

${ }^{23}$ Cette période voit apparaître une kyrielle de populistes mêlant discours fascisant et promesses d'avenir radieux, dont les exemples les plus révélateurs sont Franjo Tudjman en Croatie, Vojislav Šešelj en Serbie, etc.

${ }^{24}$ La LC de Slovénie, dirigée par Milan Kučan, rebaptisée Parti de la réforme démocratique (ZSK) en décembre 1989, se présentait aux élections avec le slogan : « L'Europe maintenant ! ". L'opposition la plus sérieuse, quoique sans différence fondamentale dans leurs projets politiques (si ce n'était dans la proposition de référendum rapide sur l'indépendance de la Slovénie), était une coalition de sept partis, DEMOS, dirigée par Janez Pučnik. Les élections du 8 avril 1990, sur le mode proportionnel, voyaient la victoire de la coalition DEMOS, mais l'élection de Milan Kučan à la présidence de la République. En Croatie, seconde république à organiser des élections pluripartites en avril-mai 1990, la LC de Croatie, rebaptisée Parti du changement démocratique, dirigée par Ivica Račan, s'opposait à l'Union démocratique croate (HDZ) de Franjo Tudjman. La victoire de la HDZ, sous le slogan " Nous seuls décidons de notre avenir " ("Odlučimo sami o našoj sudbini "), bien que courte ( $41,5 \%$ des votes), lui octroyait la majorité absolue au parlement. Tudjman fut élu Président de la République de Croatie.

25 En Macédoine, la LC de Macédoine cédait la victoire à l'Organisation révolutionnaire intérieure macédonienne-Mouvement démocratique de l'unité populaire macédonienne (VMRO-DPMNE), parti nationaliste modéré, au parlement en novembre 1990. Kiro Gligorov fut élu Président de la République. Les élec- 
voyaient la victoire des communistes sur les partis d'opposition ${ }^{27}$. Dès lors, il apparaissait, aux yeux des communautés des autres républiques, comme dans la perception de l'évolution de la Yougoslavie à l'étranger, que seuls en Serbie et au Monténégro, les communistes s'étaient maintenus au pouvoir.

En réalité, l'idée de communisme dans son idéologie, comme dans sa pratique, n'était ni le moyen ni la fin recherchée des cadres politiques au pouvoir. En revanche, cette vision fausse a longtemps prévalu dans la presse, permettant d'isoler une Serbie et un Monténégro réactionnaires, tenants d'un dogmatisme stalinien à consonance nationaliste. Or, à des degrés sensiblement différents, les partis nationalistes ont remporté les élections dans toutes les républiques. Les premières mesures des nouveaux gouvernements républicains ont été de modifier leur Constitution respective, afin d'accélérer le processus de désintégration de la fédération.

La Slovénie, la Serbie et la Croatie étaient à l'origine de la création de la Yougoslavie. Elles sont aussi à l'origine de sa destruction. Dans sa gestation nationale, chacune devait gérer et assumer la politique suivie depuis la fin des années 1980. En Slovénie, les élections confirmaient un processus de séparation de la fédération pensé et appliqué depuis le milieu des années 1980 : loin d'être le prélude d'une politique sécessionniste, elles étaient le résultat d'une maturation nationaliste et une étape vers l'indépendance. En Serbie, la gestion chaotique du Kosovo depuis 1987 a, d'une part, radicalisé les populations albanaises (ou shqiptar) en les convainquant que leur avenir ne se situait plus par l'élévation du Kosovo au statut de république mais par l'indépendance. D'autre part, elle a alimenté les arguments irrédentistes des autres républiques vis-àvis de la volonté hégémonique de la Serbie. En Croatie, les mêmes motivations nationalistes ont amené les dirigeants politiques à durcir leur politique vis-àvis des Serbes de Krajina et de Slavonie. Tout en réclamant le droit de sécession

tions en Bosnie-Herzégovine, le 18 novembre 1990, ont vu la victoire des représentants des différentes nations composant cette république, la SDA de Alija Izetbegović, le SDS de Radovan Karadžić, et le HDZ de Stjepan Kljujić. La LC de Bosnie-Herzégovine disparaissait du paysage politique.

${ }^{26}$ Dans le même ordre d'idée, la fédération n'a pu amender la constitution fédérale que le 8 août 1990, afin de permettre la pluralité des listes électorales, soit après les élections dans les Républiques de Croatie et de Slovénie. Cela explique en partie le fait que le gouvernement fédéral n'ait pu présenter son candidat (Ante Marković) que très tard et dans des conditions chaotiques. D'autre part, les premières dispositions des nouveaux gouvernements républicains ont créé un climat de méfiance et de troubles tels que par la suite, l'électorat a suivi le courant nationaliste généralisé.

${ }^{27}$ La LC de Serbie, rebaptisée Parti socialiste serbe (SPS ou Socijalistička Partija Srbije) le 16 juillet 199o, remporte les élections à une large majorité. Le scrutin offrait le choix considérable de 52 partis, mais dont le seul opposant sérieux se résumait au Parti serbe du renouveau (SPO ou Srpski Pokret Obnove), de Vuk Drašković, aux accents nationalistes très prononcés. Slobodan Milošević fut élu Président de la République de Serbie. Au Monténégro, l'élection propulsait Momir Bulatović, président du Parti communiste, dès le premier tour. 
de la fédération dans le cadre des frontières existantes, la Croatie menait une politique de déstabilisation de la Bosnie-Herzégovine par un soutien explicite aux nationalistes croates d'Herzégovine.

En 1990, les instances fédérales existent encore formellement. Le gouvernement fédéral, marquant sa volonté de maintenir l'unité comme la constitutionnalité de la fédération, s'implique dans la crise du Kosovo, poursuit la réforme économique engagée depuis 1989 et se pose en arbitre dans les différends inter-républicains. Loin d'observer une neutralité positive, les instances fédérales multiplient les projets de réformes constitutionnelles comme institutionnelles. Si le gouvernement ${ }^{28}$ de Branko Mikulić (1984-1988) subissait l'étroite opposition des représentants républicains, paralysant la moindre tentative de changement (perçue comme bouleversement), le gouvernement d'Ante Marković fut tout autre. Ante Marković prévoyait, à terme, de faire de la Yougoslavie " un pays occidental démocratique avec un système capitaliste ". En d'autres termes, Marković prônait le renversement d'une économie socialiste au profit d'une économie de marché afin d'ancrer la Yougoslavie au marché mondial occidental ${ }^{29}$. Fondamentalement, le coût social réclamé par la politique volontariste du gouvernement fédéral se transforme en drame social qu'aucun des dirigeants républicains n'est en mesure d'assumer, et qui entre en contradiction avec les promesses électorales qui ont amené chacun des dirigeants au pouvoir. Par ailleurs, le processus de séparation des républiques est d'ores et déjà engagé.

Les émeutes qui endeuillent le Kosovo en 1989 provoquent une double réaction. D'une part, une rupture dans les relations serbo-albanaises, d'autre part, une effervescence telle, en Serbie ${ }^{30}$, que la présidence fédérale vote le couvre-feu et autorise le déploiement d'unités militaires pour maintenir l'ordre dans la région. Cette décision (acceptée par le gouvernement fédéral

\section{SIV, Savezno Izvršno Veče, ou Conseil exécutif fédéral.}

29 Les mesures budgétaires et anti-inflationnistes du gouvernement Marković ont porté leurs fruits à court terme. L'inflation, à trois chiffres, est résorbée en une année d'application du train des réformes, permettant, dès 1990, de rendre le dinar à nouveau convertible. Ces mesures d'urgence restent pourtant superficielles ; les plans de restructuration de l'économie se heurtent à la mauvaise volonté des dirigeants politiques des républiques pour des raisons différentes d'une région à l'autre. Les républiques riches, essentiellement la Slovénie et la Croatie, s'opposaient à Marković pour des raisons tant politiques qu'économiques. Elles refusaient toute recentralisation de la fédération pour les mêmes raisons que le gouvernement fédéral mais elles optaient pour une recentralisation au nom du libéralisme républicain. Les républiques pauvres, la Bosnie-Herzégovine, la Macédoine et la Serbie (tout autant pour des raisons politiques), conscientes de leur retard de productivité comme de rentabilité, mesuraient les conséquences politico-sociales de ces réformes. D'autre part, la JNA, dont l'essentiel du budget comme du train de vie dépendait de la fédération, redoutait des coupes franches oblitérant ses " besoins " supposés. Enfin, l'impact social inévitable des réformes, incluant une dégradation accrue du niveau de vie, constamment en baisse depuis le début des années 1980, rendait le gouvemement impopulaire.

$3^{\circ}$ Le 27 février 1989, à Cankarjev Dom, à Ljubljana, les dirigeants politiques slovènes prennent fait et cause pour les mineurs albanais, en grève depuis le début du mois, affirmant que les grévistes sont les 
sous la pression de la foule comme en raison de l'influence croissante de la Serbie), de même que les amendements constitutionnels qui permettent à la Serbie de réintégrer le Kosovo sous son influence directe, permettent à la Slovénie de légitimer ses propres amendements constitutionnels en vue de se séparer de la fédération. Les nombreuses sessions réunies en vue de réfléchir sur la constitutionnalité des amendements républicains et leurs modalités étaient, en réalité, lourdes de menaces et de conséquences ${ }^{31}$. Elles marquent la rupture définitive des républiques avec la fédération. Celles-ci aboutissent à la $14^{\text {ème }}$ session de la LCY, du 20 au 22 janvier 1990 : le désaccord profond qui sépare le projet " fédéral " et centraliste de la Serbie, au projet de " fédération asymétrique " de la délégation slovène, aboutit au report de la session après que la délégation slovène, suivie de la délégation croate, a quitté le congrès. La LCY ne se réunira plus ; cette session marque la dissolution de cette instance ainsi que la mort de la fédération ${ }^{32}$. Tandis que les manifestations de masse se prolongent en Serbie, la crise politique opposant la Serbie et la Slovénie se matérialise par la rupture des liens économiques entre ces deux républiques 33 . Ces décisions inconstitutionnelles sapent la crédibilité et la légitimité de la fédération, et détruisent en même temps le programme de réformes économiques mis en place par Ante Marković.

\section{L'ULTIME TENTATIVE DE SAUVETAGE : LA MÉDIATION INTERNATIONALE. ERREURS ET CONSÉQUENCES}

Face à la décomposition de l'espace politique yougoslave, les milieux dirigeants aux États-Unis et en Europe manifestent (en dehors des représentations diplomatiques) un manque de cohérence et de connaissance préjudiciable à

\footnotetext{
véritables " défenseurs de la Yougoslavie issue de l'AVNOJ ". Cette intervention, télévisée en Serbie, provoque un choc dans l'opinion publique et un mouvement de mécontentement rassemblant plusieurs dizaines de milliers de manifestants devant le parlement fédéral, réclamant une intervention énergique pour briser la grève et rétablir l'ordre au Kosovo.

${ }^{31}$ La démarche essentiellement républicaine de la Slovénie interdisait une démocratisation de la fédération par le vote fédéral en première instance. D'autre part, si la Slovénie avait le droit de modifier sa Constitution sans l'accord des instances fédérales, cela lui procurait un pouvoir au moins égal à cette dernière.

${ }^{32}$ Malgré le discours rassurant d'Ante Marković après la session, affirmant que " la Yougoslavie continuera d'exister ", la dissolution de la LCY détruit l'un des verrous institutionnels, et le ferment de l'unité yougoslave avec la JNA.

${ }^{33}$ Dans le prolongement des " meetings de la vérité ", encouragés par le gouvernement Milošević, des manifestations de Serbes prévues à Ljubljana sont bloquées à la frontière de cette dernière république. Par mesure de rétorsion, la Serbie annonce le $1^{\mathrm{er}}$ décembre 1989 un embargo sur les produits slovènes en Serbie. La Slovénie répond par des contre-mesures le 22 février 1990.
} 
tous les tenants d'une Yougoslavie unie. Jusqu'en 1991, l'unité de la fédération est constamment réaffirmée par des discours forts et un soutien explicite au gouvernement fédéral yougoslave. Les bouleversements politiques en URSS et en Europe de l'Est encouragent les États-Unis à soutenir les réformes politiques et économiques de la Yougoslavie et son intégration dans l'économie de marché. Néanmoins, la situation au Kosovo est stigmatisée aux États-Unis, et source de sanctions économiques, plongeant un peu plus le gouvernement fédéral dans un cul-de-sac politique et économique ${ }^{34}$. D'autre part, les deux axes essentiels des pays occidentaux vis-à-vis des pays d'Europe de l'Est - " démocratie " et “ économie libérale "-les amènent, après les élections républicaines de 1990, à différencier les différents pouvoirs politiques de la Yougoslavie en privilégiant les interlocuteurs les plus réceptifs aux cadres occidentaux, nonobstant la dérive nationaliste des républiques de Slovénie et de Croatie. Cette distanciation entre mouvements " démocratiques " et dérive autoritaire, à laquelle s'ajoute la visible délitescence des instances fédérales, amène peu à peu les pays occidentaux à isoler la fédération au profit d'une transition pacifique de la Yougoslavie vers le " nouvel ordre mondial ». Cette vision simpliste du cadre politique yougoslave se révèle à partir de 1991 aussi lourde de conséquences pour l'espace yougoslave, qu'un nœud inextricable pour la diplomatie occidentale.

Il serait réducteur de résumer la politique slovène à une volonté constante et permanente de velléités sécessionnistes. Néanmoins, la Slovénie, par un travail de sape de la fédération, tendait à s'affranchir de la rigidité du cadre fédéral afin d'intégrer l'espace politique et économique ouest-européen. En ce sens, la substance de la vision slovène se matérialise concrètement dans ses propositions de "fédération asymétrique ". À terme, le sous-espace yougoslave s'intégrerait suivant le même principe que la Communauté européenne à ce cadre politique et économique plus vaste : c'est-à-dire, une addition d'ensembles politiques, mus par la volonté commune d'unifier les intérêts économiques, afin de mieux les défendre dans un monde globalisé. Chacune des républiques produirait en fonction de ses possibilités, augmentant le produit global brut de l'ensemble, les dividendes se répercutant forcément à ses différentes composantes et selon son investissement. Il était évident que la Slovénie, la république la plus " riche " de Yougoslavie, dont l'industrie de transformation bénéficiait des matières premières à bas prix des républiques "pauvres ", capable de s'insérer à l'économie de marché, polarisait sa politique suivant ses intérêts 35 . Il était, d'autre part, tout aussi logique que dans un espace dit " so-

\footnotetext{
34 D'autant plus que la Yougoslavie n'est plus, en 1990, un pays stratégique de premier plan pour les ÉtatsUnis, ce qui les pousse à adopter la politique du wait and see.

35 La Slovénie avait noué des liens financiers et commerciaux dès le milieu des années 1980 avec la plupart des pays ouest-européens, notamment l'Autriche et l'Italie, par une ouverture aux capitaux étrangers, des associations bancaires, etc., lui offrant de réelles opportunités économiques.
} 
cialiste ", elle ait rencontré une opposition farouche à cette évolution libérale, dont les conséquences sociales se ressentiraient essentiellement dans les régions les moins à même d'amortir la transition politique et économique.

À partir de 1990, les dirigeants slovènes, conscients de l'évolution politique réactionnaire dans les autres républiques ${ }^{36}$, optent pour le retrait de la fédération. La négation de la fédération et le soutien aux éléments les plus destructeurs en sont une manifestation concrète. Le cadre institutionnel se constitue progressivement à partir de $1989^{37}$, et se prolonge jusqu'au référendum sur l'indépendance en décembre 1990. Parallèlement, la Slovénie se démarque financièrement et militairement. Le renforcement de la défense territoriale (TO), par l'achat d'armes ${ }^{38}$, le retrait des conscrits et des cadres militaires slovènes de la JNA, permettaient la mise en place d'un complexe militaro-industriel autonome, ainsi que la prise en charge des postes douaniers, sources de revenus et symboles de souveraineté. Les affrontements en Slovénie entre la défense territoriale slovène et la JNA en juin-juillet 1991 marquent une étape fondamentale dans l'évolution vers les conflits armés de la Yougoslavie. Outre la campagne de propagande intense en Slovénie, dont l'écho se répercute largement en dehors des frontières de la Yougoslavie, le résultat de cette " miniguerre d'indépendance " s'analyse sur plusieurs niveaux : d'une part, la JNA et, par son intermédiaire, la fédération sont définies comme des occupants étrangers 39 ; d'autre part, la victoire diplomatique et militaire de la Slovénie pousse la Croatie, et par réaction en chaîne la Bosnie-Herzégovine et la Macédoine, à formuler leur retrait de la fédération. Enfin, la JNA, humiliée, vidée de ses éléments multinationaux, s'oriente définitivement vers une politique serbe, dont les conséquences sur l'avenir des autres républiques seront désastreuses.

La Croatie connait en 1990-1991 un double phénomène : elle renforce son cadre institutionnel et suit la Slovénie dans la poursuite de l'indépendance par le rejet de la fédération, mais se trouve parallèlement morcelée territorialement, ce qui par là même nie son existence en tant qu'État. Ainsi, l'évolution de

${ }^{36}$ Une évolution réactionnaire que la Slovênie a soutanue et favorisée à partir de la seconde moitié des années 1980, notamment en donnant un écho favorable à l'irrédentisme albanais au Kosovo, l'influence politique qu'elle a exercée en Croatie, etc.

37 Notamment la réflexion sur l'indépendance de la Slovénie en juillet 1989, le " choix national ", discuté aussi bien dans les milieux intellectuels que dans la presse.

${ }^{8}$ Sur ce point, voir Silber (Laura), Little (Allan), The Death of Yugoslavia, London : Penguin Books, 1995 pp. $105-118$.

$39 \mathrm{Or}$, la fédération existant encore officiellement, la JNA ne peut en aucun cas (si ce n'est à travers des preuves de crimes de guerre ou de politique concrète de ségrégation, ce qui n'était pas le cas) être considérée comme une force d'occupation. Néanmoins, la propagande adroite de la Slovénie convaincra les chancelleries occidentales de la légitimité slovène contre l'illégitimité de la JNA. 
la Croatie se situe sur un plan institutionnel et politique dans un premier temps $4^{\circ}$, puis évolue vers une confrontation militaire par la suite.

Le vote de la Constitution croate de décembre $1990^{41}$, niant les droits politiques de la " minorité " serbe, puis la politique constante d'exclusion des Serbes des entreprises publiques comme de l'administration $4^{2}$, alimentent les foyers de tension dans les régions où les Serbes sont majoritaires. Plus que la volonté de Franjo Tudjman d'imposer à l'ensemble de la population la reconnaissance de l'État croate, c'étaient les modalités de son application par la négation des droits des minorités qui ont motivé les Serbes à se rebeller. Ainsi, se sont érigées, dès l'été 1990, des barricades dans les principales villes et lieux-dits à majorité serbe, niant l'autorité de l'État, comme la volonté d'affirmer d'une part, l'autonomie régionale, et d'autre part, le souhait de rester dans le cadre de la fédération yougoslave. La récupération progressive des revendications serbes par l'appareil d'État de Belgrade43, puis après les événements de Slovénie, le rapatriement d'une partie de l'armement et des effectifs militaires en Croatie, font exploser les restes de cadre et d'idée fédérale en Yougoslavie. Dès lors, à une " révolte " qui pouvait apparaître légitime, se superpose une guerre de conquête implantée par les cadres dirigeants de la JNA, avec l'aval de la Serbie44.

La Bosnie-Herzégovine, et la Macédoine dans une moindre mesure, étaient tributaires de l'évolution de la Slovénie et de la Croatie. Républiques les plus fragiles, du fait de leur composition nationale comme de leur équilibre économique, elles restaient attachées à l'idée de fédération yougoslave. De fait, chacune a évolué en fonction des circonstances et des événements, alternant projets d'union des républiques au sein d'une fédération réformée, et mise en place de structures institutionnelles permettant l'indépendance. D'autre part,

40 Qui aboutit à la déclaration d'indépendance, le 25 juin 1991.

41 Dite " Constitution de Noël n, car adoptée le 24 décembre 1990.

42 Tudjman misait sur la police afin de construire un embryon d'armée nationale, le ministère de l'Intérieur étant constitué d'une proportion non-négligeable de Serbes. De même, la politique d'exclusion constante de ces derniers au profit de Croates impliquait des conflits ouverts au sein de la hiérarchie de la police, ainsi que des révoltes de ses effectifs. La " guerre de la police n, qui se prolonge jusqu'à la sécession de la Krajina, en août 1990 et au-delà, est le prélude de la guerre en Croatie.

43 Ainsi, Jovan Rašković, qui représentait le projet constitutionnaliste des revendications serbes, est remplacé en août 1990 par Milan Babić, proche des cercles politiques de Milošević, et partisan du rattachement de la Krajina à ce qui reste de fédération " yougoslave ".

44 Durant l'année 1990, la JNA poursuit une phase de " neutralité positive " vis-à-vis des Serbes de Krajina (sans couper le dialogue avec Zagreb), puis s'engage militairement par le ravitaillement en armement et en " volontaires " du côté serbe, à partir de 1991. L'évolution nationaliste de la JNA, n'a pas suivi une évolution naturelle, comme les événements ultérieurs, ainsi que son " assassinat médiatique " pourraient le faire croire. Constitutionnalistes, les cadres dirigeants de la JNA (avec Kadijević à leur tête) avaient besoin de l'aval de la Présidence (qui ne donnera pas son accord, soumis au vote des membres de la Présidence collective) afin de " briser " les velléités sécessionnistes de la Slovénie et de la Croatie, par l'intermédiaire d'un éventuel coup-d'État. Ainsi, ce sont les nouveaux cadres de la JNA, à partir de 1991, lorsqu'elle sera presque exclusivement serbe, qui réorienteront son engagement " pro-serbe ". 
ces deux républiques connaissent une fragmentation communautaire qui préfigure une homogénéisation croissante des populations, ainsi qu'une défiance commune vis-à-vis de l'État de droit.

La victoire du VMRO-DPMNE aux élections républicaines aurait pu faire voler en éclat le cadre étatique macédonien. Mais la prudence de Kiro Gligorov, ainsi que l'attachement de Vasil Tupurkovski45 à l'unité de la fédération, ont maintenu l'équilibre fragile entre la population macédonienne slave et albanaise de Macédoine ${ }^{46}$. Ainsi, la politique de la Macédoine à partir de 1990 se situe essentiellement sur deux niveaux : d'une part, le vote de la constitution de la Macédoine redéfinit celle-ci en tant que l'État de la " nation macédonienne ", déniant aux Albanais le statut de nation constitutive mais leur accordant le statut de " minorité ". D'autre part, son engagement à la vision confédérale de la Yougoslavie, notamment à partir de $1991^{47}$, reste, dans son essence, pro-yougoslave, ce qui évite à la Macédoine de s'embraser dans un conflit ethnique.

$\mathrm{Au}$ lendemain des élections du 18 novembre 1990, la Bosnie-Herzégovine est gouvernée par une coalition de trois partis nationalistes $4^{8}$, fondée sur la " clé nationale ". Cette coalition " contre nature " paralyse rapidement les institutions bosniaques tout en livrant les populations aux contradictions de leurs élites politiques respectives : d'une part, la radicalisation des discours nationaux alimente la méfiance et les affrontements communautaires 49 et, d'autre part, le nécessaire attachement affiché de ces élites à une Yougoslavie fédérale, tend à persuader la population que cette situation de "libanisation " est l'unique solution pour sauvegarder une Bosnie-Herzégovine unie. Cette situation de fait, entretenue par la Croatie et la Serbie ${ }^{50}$, aboutit à un morcelle-

\footnotetext{
45 Membre de la Présidence collégiale yougoslave en 1990-1991.

${ }^{46}$ Les Albanais de Macédoine ayant massivement boycotté les recensements de population de 1990, ils étaient estimés à environ $25 \%$ de la population. Certaines estimations leur donnaient de 30 à $33 \%$.

$47 \mathrm{La}$ “ Plate-forme sur l'avenir de la Fédération yougoslave n, en janvier 1991, fut un compromis entre la vision fédérale serbe et confédérale slovène. Malheureusement, ce projet fut présenté dans une période où la Slovénie, la Croatie, de même que la Serbie avaient déjà opté pour la mort de la fédération, et la poursuite de leur voie nationale.

$4^{8}$ Le SDA de Alija Izetbegović, le SDS, de Radovan Karadžić, et le HDZ de Stjepan Kljujić.

49 Les premiers affrontements graves ont lieu à Foča, bourgade à l'est de la Bosnie-Herzégovine le 11 septembre 1990, opposant des Serbes à des Musulmans.
}

$5^{\circ}$ Aussi Tudjman affirmait, à propos de la Bosnie-Herzégovine : « La Bosnie fait historiquement partie de la Croatie, ainsi que de sa sphère d'influence géopolitique. Ce n'est pas seulement le fait que des Croates vivent en Bosnie, mais la plupart des Musulmans de Bosnie se considèrent eux-mêmes, en tant que Croates ", in Zimmermann (Warren), Origins of a Catastrophe : Yugoslavia and Its Destroyers, pp. 74-75. Milošević, de son côté, transposait la question de la Bosnie-Herzégovine sur le plan politique, dans une optique " fédérale ", affirmant que "la meilleure solution est de vivre dans un seul pays ", aussi, l'on ne peut pas séparer des populations (en l'occurrence les Serbes) contre leur gré de la fédération, ce qu'il " n'autorisera pas " (in Silber (Laura), Little (Allan), op. cit., pp. 131-132). 
ment territorial croissant et à l'explosion de la Bosnie-Herzégovine lorsque le gouvernement fédéral, isolé des gouvernements républicains, ne pourra plus garantir l'unité de la Yougoslavie et un projet politique applicable. Lorsque le SDA et le HDZ s'unissent à partir d'octobre 1991 pour appuyer l'indépendance de la Bosnie-Herzégovine, la guerre pour les États nationaux est déjà perceptible sur le terrain.

Milošević, en fin tacticien politique, avait placé les élections en Serbie sur le plan de l'unité de la fédération comme du nationalisme serbe. Ainsi, pour garder le pouvoir, il maintenait les options fédérale et républicaine, sans exclure la possibilité de renforcer l'une ou l'autre. La délitescence brutale de la fédération, à partir de février 1991, suivie des événements de mars 1991, ainsi que son impossibilité d'en prendre le contrôle, aboutit à une réorientation de sa politique vers la formation d'une entité territoriale sous son contrôle exclusif, quelle qu'en soit son esprit et sa forme. Le Monténégro, désormais excroissance de la Serbie, ne se conçoit désormais plus indépendamment de sa république Mère.

L'effervescence nationaliste en Serbie, travaillée à grande échelle depuis l'apparition de Milošević à la tête de l'appareil d'État en Serbie, révèle son aspect ambigu et destructeur, même pour son instigateur. Le 9 mars 1991, une foule de plusieurs dizaines de milliers de manifestants, conduite par les milieux universitaires, réclame la démission de Milošević et le changement du régime $^{51}$. Cette situation insurrectionnelle amène Borisav Jović ${ }^{52}$, à l'instigation de Milošević, à faire appel à l'armée pour disperser les manifestants 53 . Cet événement crucial amène la présidence yougoslave à réfléchir sur la politique à adopter sur l'ensemble du territoire yougoslave. Le 12 mars, une réunion du præsidium fédéral devait faire le point sur la situation en Yougoslavie et adopter des résolutions applicables sur l'ensemble du territoire, notamment la proclamation de l'état d'urgence et la résolution de la crise en Croatie ${ }^{54}$. Le désaccord entre les membres de la présidence concernant la façon dont devait être

${ }^{51}$ Les manifestants, aux cris de " À bas la démocratie rouge ", "Slobo Saddame ! ", réclamaient une démocratisation du régime, où se mêlait tout autant la revendication de régler la question nationale serbe au Kosovo, que l'opposition à la guerre en Yougoslavie.

52 Borislav Jović, représentant serbe de la Présidence collégiale de la Yougoslavie de mai 1990 à mai 1991, était un proche de Milošević.

53 La façon dont Jović a fait pression sur les membres de la Présidence, notamment Vasil Tupurkovski, représentant de la Macédoine, et Bogič Bogičević, représentant serbe de la Bosnie-Herzégovine, afin de voter l'intervention de l'armée, fait l'objet d'une abondante littérature. Voir notamment les mémoires de Jović (Borislav), Komadanje Jugoslavije (Le morcellement de la Yougoslavie), Beograd : Politika, 1992, pp. 92-118.

54 Cette réunion comprenait Borislav Jović, Vasil Tupurkovski, Bogič Bogičević, représentant serbe de la Bosnie-Herzégovine, Stipe Mesić, représentant de la Croatie, Riza Sapundžija représentant du Kosovo, Jugoslav Kostić, représentant de Voïvodine, Nenad Bučin, représentant du Monténégro et Veljko Kadijević, membre de la présidence en tant que ministre de la Défense (Janez Drnovšek, représentant de 
résolue la crise, eut une double conséquence : l'implosion de gouvernement fédéral et sa chute définitive, ainsi que la conviction pour Milošević que la fédération faisait désormais partie du passé. Dorénavant, la politique de la Serbie ne s'attacherait plus à la sauvegarde de la Yougoslavie, mais à assurer la sécurité des Serbes sur l'ensemble de l'espace yougoslave (ce qui concernait essentiellement les Serbes de Croatie et de Bosnie-Herzégovine), et à les regrouper dans un espace commun. Le 25 mars 1991, Milošević et Tudjman se rencontraient à Karadjordjevo, afin de déterminer leur politique commune vis-à-vis de la fédération et de la Bosnie-Herzégovine 55 .

Durant l'année 1991, la guerre s'étend progressivement sur le territoire yougoslave. La Slovénie ayant négocié son retrait de la fédération, la guerre reste symbolique. En revanche, la Croatie subit une escalade dramatique du conflit armé. La Communauté européenne, dans l'euphorie du renforcement de ses institutions, met sa diplomatie à l'épreuve, convaincue qu'une solution négociée sous son égide réglerait le conflit en quelques mois. Face aux maigres résultats diplomatiques, divers acteurs se superposent et se contredisent fin 1991 : la Communauté européenne, certains de ses membres menant une politique autonome, et enfin l'ONU. La reconnaissance prématurée de la Slovénie et de la Croatie, à partir de 1992, a deux conséquences concrètes : la mort de la Yougoslavie, après 74 ans d'existence, et une guerre inter-nationale de conquêtes territoriales placée sous l'égide d'instances internationales, mal préparées à une intervention, mal négociées, et impuissantes à séparer les belligérants.

La Slovénie déclarait son indépendance le 25 juin 1991, suivie de la Croatie. L'intervention militaire de la JNA, et la " guerre d'indépendance " qui dura dix jours, du 28 juin au 7 juillet, fut déterminante dans l'évolution des

la Slovénie, craignant un coup d'État, était absent). La réunion devait permettre le règlement du problème du désarmement de l'ensemble des unités paramilitaires en Croatie afin d'éviter les affrontements croissants sur son territoire, ainsi qu'une réponse appropriée aux événements de Belgrade. En fait, cette réunion s'est révélée être un vote " pour " ou " contre " la prise en main de l'armée de l'ensemble du territoire ; autrement dit un coup d'État permettant de clarifier la situation sur le terrain et pacifier la Yougoslavie. Les partisans du coup d'état " constitutionnel n, c'est-à-dire les représentants des républiques contrôlées par la Serbie, n'ont pas convaincu le membre supplémentaire, nécessaire à la majorité des votants, de voter cette résolution. Une partie de l'avenir de la Yougoslavie s'est donc jouée ce jour-là.

55 Le contenu de cette rencontre, encore partiellement inconnu mais désormais établi quant à ses conséquences, le vraisemblable accord sur l'effondrement de la fédération et le partage de la BosnieHerzégovine, se laisse entrevoir à travers les différentes rencontres ultérieures des deux dirigeants (Mesić affirme, dans ses mémoires, qu'ils se sont vus 52 fois en trois ans), et leur politiques respectives. Miloš Minić, ancien rédacteur en chef du quotidien de Zagreb, Vjesnik, a effectué un travail de recherche considérable dans la presse afin de recouper les différents morceaux du puzzle de Karadjordjevo, et publiẻ dans son ouvrage, Minić (Miloš), Dogovori u Karadjordjevu o podeli Bosne i Hercegovine (Les accords à Karadjordjevo sur la partition de la Bosnie-Herzégovine), Sarajevo : Rabić, 1998. 
guerres yougoslaves ${ }^{56}$. Une délégation européenne, composée de Jacques Poos, Hans Van den Broek et Gianni de Michelis (la Troïka) arrivait à Belgrade le 28 juin afin de négocier la cessation des hostilités 57 . Malgré les promesses formelles, les différents partis avaient clairement défini leurs objectifs : la Slovénie ne reviendrait pas sur sa déclaration d'indépendance ${ }^{58}$, la Croatie suivrait la même voie, la Serbie ne s'opposerait pas à l'indépendance de la Slovénie 59 mais s'attacherait à protéger les Serbes dans l'ensemble du territoire yougoslave ${ }^{60}$. Ces pourparlers débouchèrent sur les accords de Brioni le 7 juillet, adoptés par la présidence yougoslave le 18 juillet ${ }^{61}$, par lesquels le statu quo fut maintenu. Cette apparente victoire diplomatique de la Communauté européenne restait de courte durée : non seulement elle ne réglait aucun des désaccords de fond ${ }^{62}$, mais la situation sur le terrain empirait chaque jour ${ }^{63}$. La prise du village de Kijevo (enclave croate dans la Krajina), puis sa destruction $^{64}$, le 26 août, modifiait la perception de l'indépendance de Franjo Tudjman, qui décrétait le même jour à la télévision croate " la guerre de libé-

${ }^{56}$ Plus qu'une guerre, cet événement s'est révélé être une campagne de relations publiques en faveur de l'indépendance de la Slovénie, tout autant qu'une campagne de dénigrement de la JNA. En brandissant le masque de la petite république agressée par une mécanique militaire réactionnaire, la Slovénie s'attirait la faveur internationale, et s'ouvrait la voie de la reconnaissance internationale. En réalité, les dirigeants slovènes étaient en contact téléphonique permanent avec les cadres de l'armée : ils connaissaient l'itinéraire des convois, leur degré d'armement et les objectifs de la JNA (la prise de contrôle des postes douaniers, l'aéroport de Ljubjana et le port de Koper).

57 L'objectif de la troïka, en trois points, prévoyait de geler la situation : la Slovénie devait revenir sur sa déclaration d'indépendance, les forces de la JNA retourner dans leur casernes et Stipe Mesić (dont l'élection à la Présidence collégiale était bloquée depuis six semaines par les représentants serbes) devait être èlu Président.

58 Elle acceptait cependant un moratoire sur l'indépendance de trois mois.

59 L'indépendance de la Slovénie avait fait l'objet d'un accord entre Milan Kučan et Slobodan Milošević le 24 janvier 1991 : la Serbie ne s'opposait pas au droit d'autodétermination des peuples si la Slovénie soutenait les Serbes de Croatie.

60 L'intervention de la JNA en Slovénie comprenait un plan A (une intervention limitée sur le territoire slovène), qui fut un fiasco, et un ẻventuel plan B (comprenant une intervention d'envergure destinée à briser la défense territoriale slovène et à arrêter les cadres politiques sécessionnistes). Borislav Jović, d'un commun accord avec Milošević, qui avait déjà décidé de porter l'essentiel des forces de la JNA en Croatie afin de soutenir la sécession des Serbes, opposa son veto au plan B lors d'une réunion extraordinaire de la présidence le 30 juin, à la surprise de Kadijević.

${ }^{61}$ Stipe Mesić, conscient que cet accord ne concernait que la Slovénie et préfigurait le morcellement de la Croatie, s'opposa, en vain, à son adoption.

${ }^{62}$ L'indépendance de la Slovénie, la position de la JNA vis-à-vis de celle-ci, l'avenir de la Yougoslavie, etc.

63 Outre que la guerre en Slovénie avait fait plusieurs dizaines de victimes ( 49 selon la Croix Rouge yougoslave), la guerre se durcissait en Croatie, en Krajina et en Slavonie orientale.

64 Avec l'aide de la JNA, qui dorénavant a clairement choisi l'option de protéger les Serbes, qui sont les seuls à la reconnaître.

65 Il s'établit dès lors une ligne de front en Croatie, comprenant la Krajina, de Knin au sud à jusqu'aux abords de Gospić, au nord, et se prolongeant à l'ouest jusqu'en Slavonie orientale, avec Vukovar. 
ration ${ }^{65}$. Dès lors, la Communauté européenne s'englue dans des négociations de cessez-le-feu, où se succèdent les conférences et les pourparlers, tandis que les États-Unis, focalisés sur la guerre du Golfe, se désintéressent de ce " problème européen "66. Le 7 septembre, alors que les combats s'intensifient en Croatie, une série de conférences s'ouvrent à La Haye afin de mettre en place un plan de paix global en Yougoslavie, sous l'égide de Lord Peter Carrington ${ }^{67}$. Tout retour à une Yougoslavie unifiée étant exclu ${ }^{68}$, il s'agissait d'aboutir à un règlement pacifique de l'indépendance des différentes républiques yougoslaves. L'échec de ces conférences, et le refus du " Plan Carrington " ${ }^{69}$ signifiaient la guerre pour la modification des frontières de l'AVNOJ, comme celui de la médiation européenne.

L'opinion publique internationale, travaillée par les médias, avait pris fait et cause pour les républiques réclamant l'indépendance ${ }^{70}$. Le siège de Vukovar ${ }^{71}$ et les bombardements sur Dubrovnik $7^{72}$ ont accéléré la pression allemande sur les pays de la Communauté européenne, réclamant la reconnais-

${ }^{66} \mathrm{Au}$ début des pourparlers, Jacques Poos, ministre des Affaires étrangères du Luxembourg, optimiste et euphorique, aurait affirmé que "l'heure de l'Europe a sonné ", paroles malheureuses qu'il regrettera par la suite, in Zimmermann (Warren), op. cit., p. 147 ; Silber (Laura), Little (Allan), op. cit., p. 159. James Baker, en visite éclair en Yougoslavie le 21 juin 1991, avait soutenu l'idée, délaissant ce " problème européen n.

${ }^{67}$ Les principes généraux d'un retour à la paix en Yougoslavie incluaient la non-modification des frontières par la force, le respect des droits des minorités et, sous la forte pression de l'Allemagne, dont le lobbying du ministre des Affaires étrangères Hans Dietrich Genscher avait convaincu le Chancelier Helmut Kohl, la reconnaissance de l'indépendance des républiques, si elles répondaient aux critères démocratiques en vigueur en Europe aux principes introduits plus haut. Afin de déterminer quelles républiques pouvaient bénéficier du soutien de la Communauté européenne, Robert Badinter fut commissionné pour étudier l'état de démocratie des républiques. Cette commission, connue par la suite en tant que "Commission Badinter ", a rendu son rapport en janvier 1992, affirmant qu'uniquement la Slovénie et la Macédoine répondaient aux critères. Elle eut très peu d'échos.

${ }^{68}$ La Slovénie étant de facto indépendante.

69 L'échec du " Plan Carrington ", très proche de la conception " asymétrique n de la Yougoslavie proposée par Alija Izetbegović et Kiro Gligorov, fut essentiellement le fait de Milošević. Tandis que la Slovénie et la Croatie s'attachaient à une configuration minimaliste de la fédération (ce qui n'excluait pas le plan, mais lui octroyait une large latitude d'interprétation), la Croatie bénéficiant en outre de la non remise en question des frontières (idée qui n'était pas valable dans le cadre de la Bosnie-Herzégovine), et la Serbie avait opté pour un expansionnisme en faveur des Serbes dans toute la fédération (le plan soulevait, d'autre part, la question des Albanais du Kosovo, prévoyant une autonomie en leur faveur, inadmissible dans l'optique nationaliste de la délégation serbe).

70 Le travail sur l'opinion publique internationale relative à cette période, relayé au niveau des gouvernements par les différents lobbys, partisans de l'indépendance de la Croatie et de la Slovénie, a fait l'objet d'études, cependant fragmentaires. Ils sont révélateurs de l'interdépendance des décisions prises par les gouvernements (notamment l'Allemagne, puis les autres pays à sa suite), et leurs implications au détriment de l'espace yougoslave.

${ }^{71}$ Le siège, entamé en septembre, aboutit à la prise des ruines de Vukovar par les paramilitaires serbes et la JNA, le 20 novembre 1991.

72 En octobre 1991. 
sance de la Slovénie et de la Croatie. L'aggravation du conflit serbo-croate, et sa transposition croissante en Bosnie-Herzégovine, ainsi que les dissensions européennes quant à la résolution du conflit, contraignent la C.E.E. à faire appel à l'ONU afin de mener conjointement les négociations de paix (Lord Carrington), et de cessez-le-feu (Cyrus Vance ${ }^{73}$ ). La conférence des ministres des Affaires étrangères de l'Union, tenue les 15 et 16 décembre 1991 admet ouvertement la reconnaissance des républiques qui veulent faire sécession, si elles remplissent les critères définis lors des conférences précédentes. Autrement dit, cette garantie de reconnaissance à terme annihilait la crédibilité et la viabilité des plans de paix formulés à La Haye, ainsi que l'ensemble des démarches effectuées par Lord Carrington (la Slovénie et la Croatie n'ayant plus aucun intérêt à trouver un accord, leur objectif d'indépendance étant atteint ; et la Bosnie-Herzégovine et la Macédoine devant les suivre, malgré les risques de guerre civile qu'elles encouraient) ${ }^{74}$. Le 23 décembre, la Slovénie et la Croatie, suivies de la Bosnie-Herzégovine, déclaraient leur indépendance, immédiatement reconnue par l'Allemagne (pour la Slovénie et la Croatie). La Serbie et le Monténégro la refusaient, et affirmaient par là même la continuité de la fédération, invitant les "régions " qui le désirent à les rejoindre dans cette " Yougoslavie " restreinte. Ainsi s'achevait l'existence de la Yougoslavie, dans le sang.

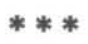

Le 11 décembre 1991 était signé à Maastricht l'" Accord sur l'union politique et monétaire des douze pays membres de la Communauté européenne ". Cet accord, historique à bien des égards, signifiait un renforcement de la Communauté européenne. Le conflit en Yougoslavie ne devait en aucun cas remettre en question sa solidarité émergente et son intégration plus poussée 75 .

73 Cyrus Vance, diplomate et ancien Secrétaire d'État américain, fut commissionné par le Secrétaire général de l'ONU, Javier Perez de Cuellar, de négocier un cessez-le-feu et le déploiement d'une force de protection des Nations unies (plus tard baptisée Forpronu).

74 Cette conférence révélait la fragilité de la diplomatie européenne, son manque d'unité (en dehors de l'Allemagne, les autres pays s'opposaient à une reconnaissance précoce des républiques), et les contradictions internes d'une Communauté encore à l'état de construction. Elle n'était que la conclusion d'une décision déjà prise auparavant. Ainsi, au sommet franco-allemand de Bonn, en réponse aux exhortations de Mitterrand à ne pas reconnaître précipitamment la Slovénie et la Croatie, le Chancelier Kohl aurait répondu, " la pression chez moi est très forte. Mon parti, mes alliés libéraux, l'Église, la presse, sans compter 500 ooo Croates qui vivent en Allemagne, tout le monde pousse n. Puis le 16 décembre, "Compte tenu de l'état de l'opinion catholique allemande - à cause des catholiques croates - , je suis obligé de reconnaître avant Noël ; sinon, je ne tiendrai pas ", in Védrine (Hubert), Les mondes de François Mitterrand. 1981-1995, Paris : Fayard, 1996, pp. 615-619.

75 Selon Hubert Védrine, Roland Dumas aurait déclaré sur l'indépendance de la Slovénie et de la Croatie, " Nous nous sommes posé [avec le Président François Mitterrand] la question de savoir s'il fallait ouvrir 
Les 15 et 16 décembre, en échange de la reconnaissance des républiques " qui le souhaitent ", l'Allemagne s'engageait à un compromis concernant l'union monétaire et la Charte sociale européenne, par rapport à la Grande-Bretagne et la France ${ }^{76}$. Ainsi, le 17 décembre, l'indépendance était formalisée dans la déclaration commune de la Communauté européenne, officiellement reconnue le 18 janvier 1992, ouvrant le premier acte d'une guerre ouverte pour des Etats nationaux 77 .

Il apparait que si le discours officiel des pays occidentaux a toujours clairement appuyé le maintien de l'unité et de l'intégrité de la Yougoslavie jusqu'en $1991^{78}$, les élections de 1990 ont très clairement permis aux différentes chancelleries de sonder les nouveaux partis au pouvoir. Les contacts diplomatiques ainsi que les déclarations publiques étant constants ; il était possible d'identifier, en fonction de l'activité politique au sein des différentes républiques, les choix auxquelles elles se sont destinées. En ce sens, le gouvernement fédéral, clairement orienté vers l'économie de marché a reçu un appui international ferme jusqu'en 1991. Par la suite, la réalité de son dysfonctionnement institutionnel ainsi que son impuissance à maintenir l'unité de la fédération n'apparaissait plus adéquate. Le choix de prendre les républiques comme interlocuteurs nécessaires s'accompagne d'une reconnaissance internationale de plus en plus concrète des dirigeants des différentes républiques. Les élections de 1990 ont créé une rupture réelle des facteurs internationaux vis-à-vis de la Yougoslavie, par opposition à la période précédente, les actes ayant précédé les discours. L'Allemagne, en ayant appuyé l'indépendance de la Slovénie et la Croatie, quasi immédiatement après les élections, a été la

une crise ; et nous avons conclu que non, même si c'était un choix difficile ", puis « Nous ne pouvions pas remettre en cause l'avenir à long terme de l'Europe - Maastricht - en raison d'un désaccord sérieux sur un conflit grave, mais qui se terminerait quand même un jour ou l'autre ", in Védrine (Hubert), op. cit., pp. 551, 620 .

${ }^{76}$ Silber (Laura), Little (Allan), op. cit., p. 198.

77 Tandis que le Chancelier Kohl applaudissait ce " grand triomphe de la politique étrangère allemande n, The Economist le définissait comme la "wreckognition ", signifiant ainsi le naufrage de la politique ètrangère européenne commune. In Zametica (John), The Yougoslav Conflict, London : The International Institute for Strategic Studies (Adelphi papers), 1992, p. 65 ; Eyal (Jonathan), Europe and Yugoslavia : Lessons from a failure, London : The Royal United Service Institute for Defense Studies, 1993, p. 50.

$7^{8}$ Déclaration de Warren Zimmermann à la Chambre de Commerce, " beaucoup d'hommes d'affaires américains suivent de près l'évolution de la situation en Yougoslavie et se demandent si u elle va s'effondrer $n$. Cela ne peut en aucun cas contribuer au développement des échanges commerciaux et représente d'autant moins un " appât " pour les capitaux étrangers. Dès le début, nous avons été en faveur de la démocratie en Yougoslavie et de son unité. L'unité est particulièrement importante d'un point de vue économique, du fait que les entreprises américaines ne s'intéressent pas aux petits marchés, de 4 à 5 millions d'habitants. L'intérêt que présente la Yougoslavie est d'être un marché de 24 millions de consommateurs n, Yugoslav Economic Review, février 1991, p. 5. 
seule à l'assumer ouvertement79. Fin novembre 1991, la Croatie connaît déjà des bouleversements démographiques conséquents : un demi million de Croates déplacés, 230000 Serbes $^{80}$, des centaines de villages et hameaux détruits, le tiers de son territoire hors de sa jurisprudence. Beaucoup d'autres suivront. La perception de l'espace yougoslave n'obéit plus qu'à une logique nationale et territoriale fondée sur une territorialisation mono-nationale de l'espace, et au pillage. La Bosnie-Herzégovine, définie comme la " petite Yougoslavie ", suit le même processus de destruction : pour les acteurs locaux comme internationaux, elle symbolise l'échec historique d'un modèle d'intégration plurinational au sein d'un espace fédéré, et constitue dès lors un réel " problème européen ".

79 En ce sens le cas de l'Allemagne est révélateur. L'Allemagne est en 1991 le premier partenaire commercial de la Yougoslavie, tant au niveau des importations que des exportations de marchandises (un tiers des devises dépend de la demande allemande). Dimitrije Boarov affirmait en juillet 1991 que, " si l'on suppose que les intérêts économiques ont une influence considérable, sinon déterminante sur les choix politiques, alors on peut considérer que le point de vue allemand, malgré les éventuelles oppositions comme ses éventuels complexes, pourrait à l'avenir avoir une influence décisive nonobstant le sentiment général de l'Europe sur la Yougoslavie. Si, par la force des choses, on fragmente la Yougoslavie en républiques, il n'est pas difficile de conclure dans quels fragments de ce pays les intérêts allemands sont les plus importants ", Vreme, 22 juillet 1991, pp. 16-17.

${ }^{80}$ Silber (Laura), Little (Allan), op. cit., p 198. 